\title{
Comparison of Effectiveness of Narrow Band Ultraviolet B Therapy Combined with $0.1 \%$ Topical Tacrolimus and Narrow Band Ultraviolet B Monotherapy in Vitiligo Treatment
}

\author{
Ameneh Yazdanfar ${ }^{1}$, Azar Pirdehghan², Bahareh Ebrahimi ${ }^{3, *}$ \\ ${ }^{1}$ Associate Professor, Department of Dermatology, School of Medicine, Hamadan University of Medical Sciences, Hamadan, \\ Iran \\ ${ }^{2}$ Associate Professor, Department of Social Medicine, School of Medicine, Hamadan University of Medical Sciences, \\ Hamadan, Iran \\ ${ }^{3}$ Resident, Department of Dermatology, School of Medicine, Hamadan University of Medical Sciences, Hamadan, Iran
}

* Corresponding Author: Bahareh Ebrahimi, Department of Dermatology, School of Medicine, Hamadan University of Medical Sciences, Hamadan, Iran. Email: b.ebrahimi.4362@gmail.com

Received: 28.05.2018

Accepted: 10.11.2018

\begin{abstract}
How to Cite this Article:
Yazdanfar A, Pirdehghan A, Ebrahimi B. Comparison of Effectiveness of Narrow Band Ultraviolet B Therapy Combined with $0.1 \%$ Topical Tacrolimus and Narrow Band Ultraviolet B Monotherapy in Vitiligo Treatment. Avicenna J Clin Med. 2018; 25(3): 127-133. DOI: $10.21859 /$ ajcm.25.3.127
\end{abstract}

\section{Abstract}

Background and Objective: Vitiligo is a depigmantation disorder that depends on genetic and non-genetic factors and results from skin melanocytes malfunction. The aim of this study was to compare the effectiveness of narrow band Ultraviolet B (NBUVB) therapy combined with $0.1 \%$ topical tacrolimus and NBUVB monotherapy in vitiligo treatment.

Materials and Methods: In this double-blind clinical trial study, 30 patients with vitiligo who had at least two symmetrical lesions were selected (60 lesions in total). The patients were randomly divided into intervention and control groups. Phototherapy with $0.1 \%$ tacrolimus ointment and with eucerin ointment (placebo) was administered to the intervention and control groups, respectively. The size of the lesions and the degree of repigmentation were evaluated with photogram and Visual Approach Slope Indicator (VASI) scoring system, respectively, at the beginning of the treatment, 1.5 and three months after the treatment. The results were then recorded in checklists and the data were analyzed in SPSS software (version 16.0).

Results: The results of the study showed that the mean age of patients was 31.60 years with the prevalence of females $(n=18,60 \%)$. The mean and standard deviation of the size of vitiligo lesion in the intervention and control groups at the beginning of the treatment were $5.41 \mathrm{~cm} \pm 2.81$ and $5.40 \mathrm{~cm}$ \pm 2.82 , respectively. Moreover, the mean size of vitiligo lesion 1.5 and three months after the treatment lesion in the intervention and control groups were $4.96 \mathrm{~cm} \pm 2.84,4.59 \mathrm{~cm} \pm 2.77,3.85 \mathrm{~cm} \pm 2.35$, and $4.66 \mathrm{~cm} \pm 2.80$, respectively $(\mathrm{P}>0.05)$. The mean score of VASI in the intervention and control groups were $0.50 \pm 0.51$ and $0.53 \pm 0.51$ at the beginning of the treatment and $1.46 \pm 1.44$ and $1.13 \pm 1.01$ after 1.5 months treatment and $2.18 \pm 1.57$ and $1.52 \pm 1.21$ after three months of treatment, respectively $(\mathrm{P}>0.05)$. Furthermore, the percentages of repigmentation in the intervention and control groups after 1.5 months were $18.25 \%$ and $14.12 \%$, and three months were $30.63 \%$ and $19 \%$, respectively.

Conclusion: The percentage of vitiligo recession in the combined treatment group was higher than that of monotherapy; however, no significant statistical difference was observed regarding the two therapeutic methods.

Keywords: Phototherapy, Tacrolimus, Vitiligo 
dof: $10.21859 /$ ajcm.25.3.127

\title{
مقايسه اثربخشى درمان تر كيبى NBUVB همر اه با پماد موضعى تاكروليموس
}

\section{I/ • در صد و روش NBUVB بلثنهايى در درمان ويتيليكو}

\author{
آمنه يزدانفر'، آذر پِيردهقان'، بهاره ابراهيمى ؟ّ."
}

' دانشيار، تروه يوست، دانشكده يزشكى، دانشعاه علوم يزشكى همدان، همدان، ايران

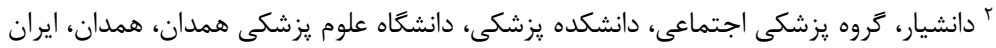

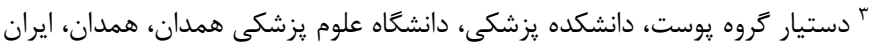

* نويسنده مسئول: بهاره ابراهيمى، كروه يوست، دانشكده يزشكى، دانشگاه علوم يزشكى همدان، همدان، ايران. ايميل:g.ebrahimi.4362@gmail.com

جكيده

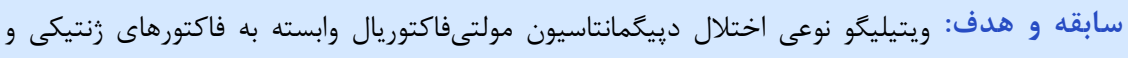

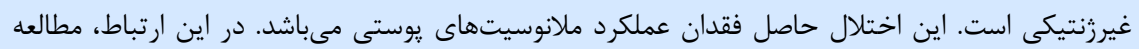

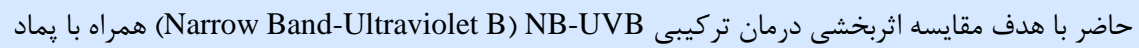

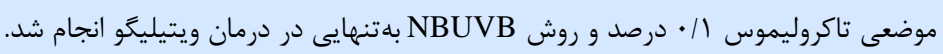

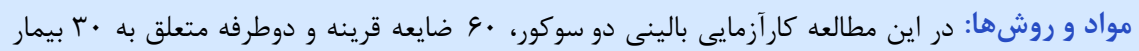

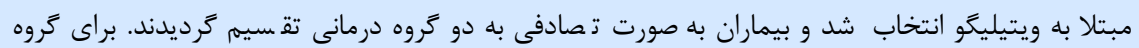

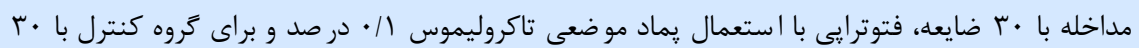

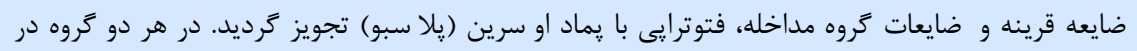

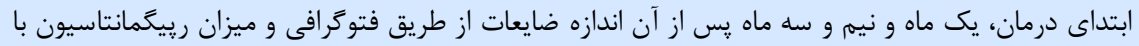

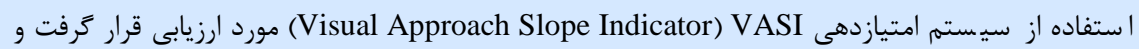

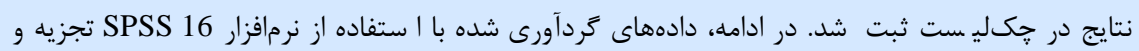
تحليل گرديدند.

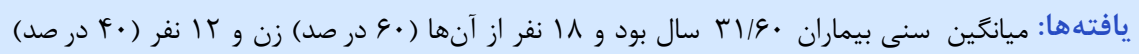

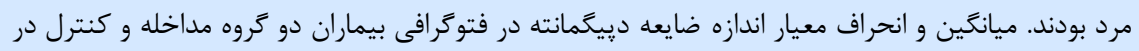

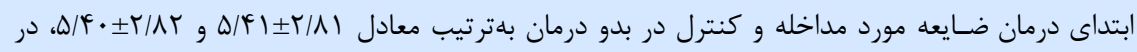

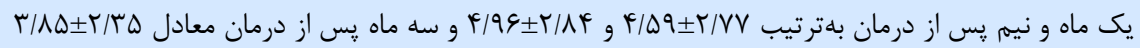

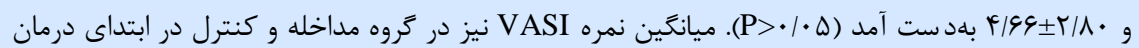

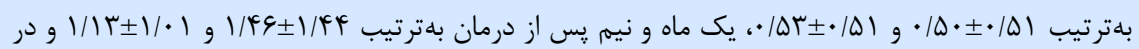
ماه ســوم در مان معادل

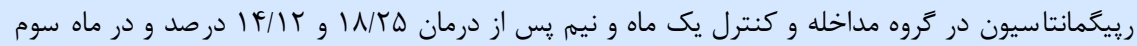

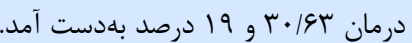

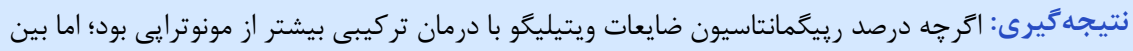

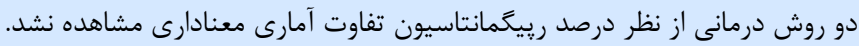
وازَّان كليدى: تاكروليموس، فتوترايى، لك و پييس

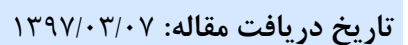

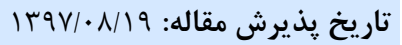
تمامى حقوق نشر براى دانشكاه علوم يزشكى همدان محفوظ است.

مقلممه

مشكلات روانيزشكى و زيبايى متعددى را ايجاد كند [س، 1]. اين

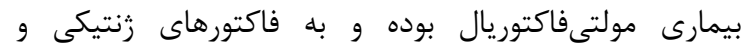
غيرزنتيكى وابسته مىباشد. در ارتباط با اين مهرم اتفاق نظر وجود بهو
ويتيليكو نوعى اختلال دييگمانتاسيون است كه حدود يك

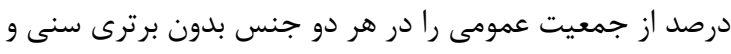

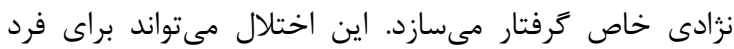


مشابه با افرادى خواهد بود كه كورتيكواستروئيد موضعى دريافت

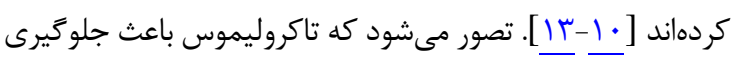

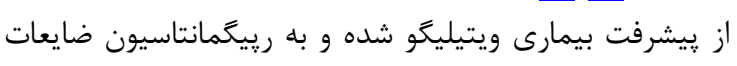

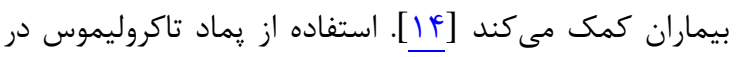

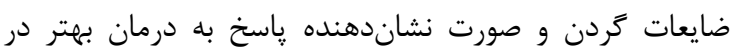

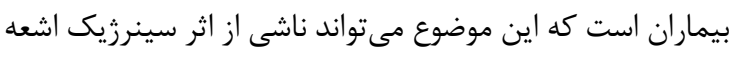

UV

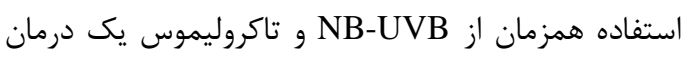

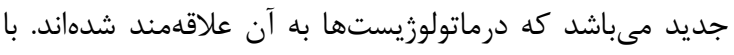

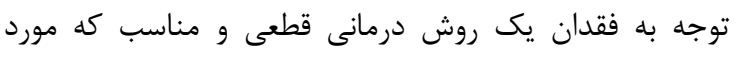

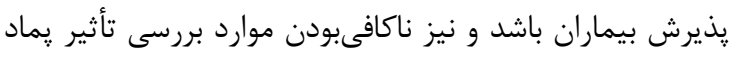

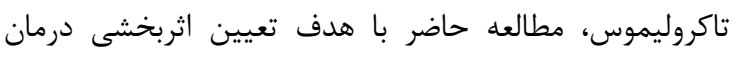

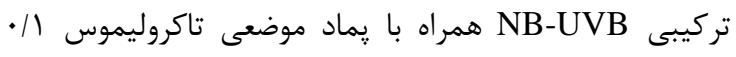

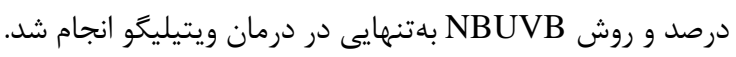

\section{مواد و روشها}

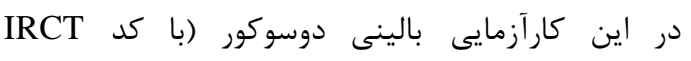

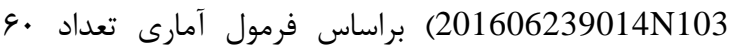
ضايعه دوطرفه قرينه ويتيليكو در اندامهاى فوقانى، تحتانى، برى

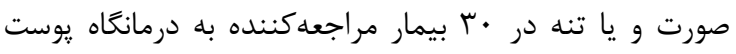

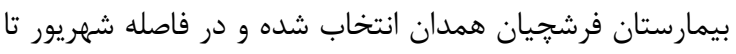

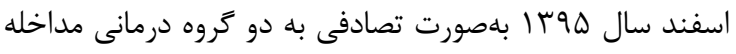

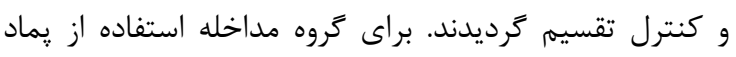

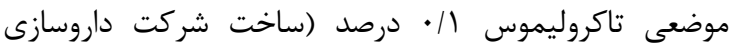
ابوريحان) بر روى ضايعات يك سمت بدن و ورول براى كروه كنترل

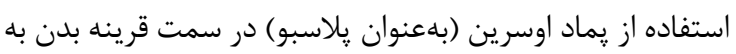

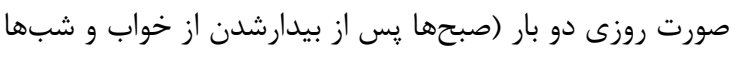

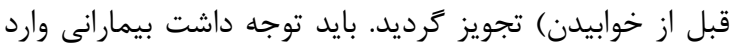

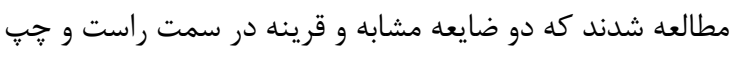

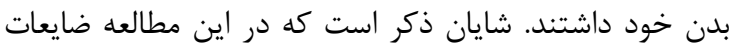

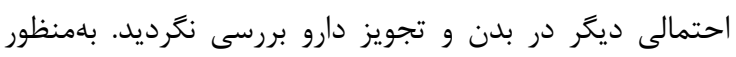

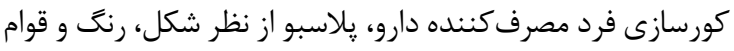

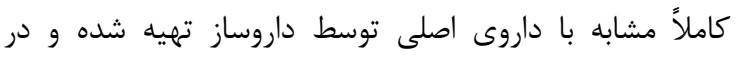

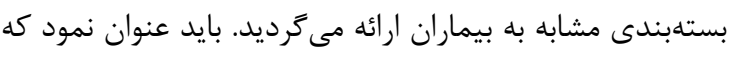

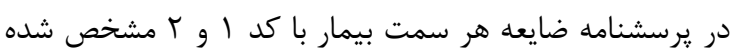

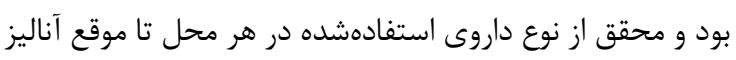

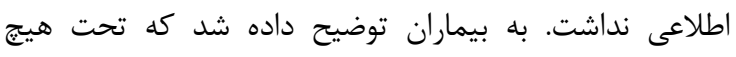

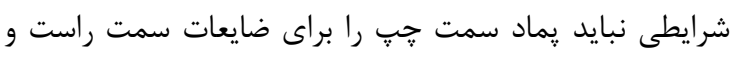

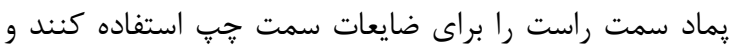

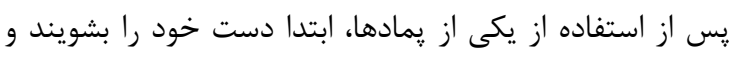
سيس اقدام به مصرف داروى بعدى نمايند.

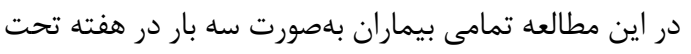

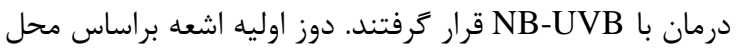

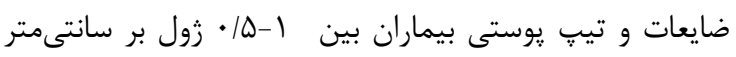

دارد كه اين اختلال حاصل فقدان عملكرد ملانوسيتهاى

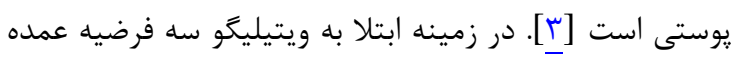
در ايجاد بيمارى شامل: فرضيه عصبى، خودتخريبى و ايمنى إنى

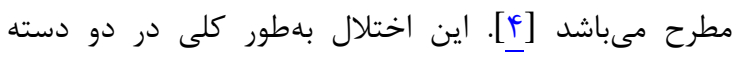

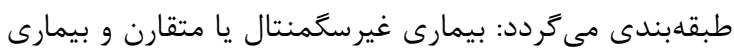

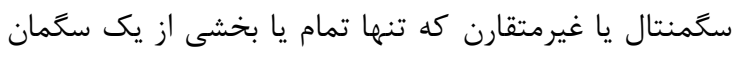

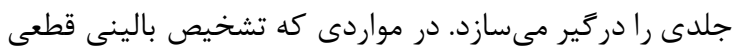

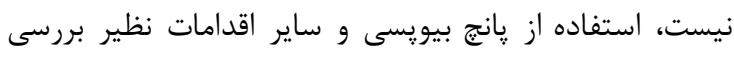

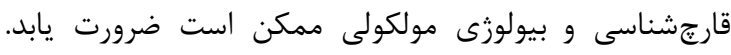

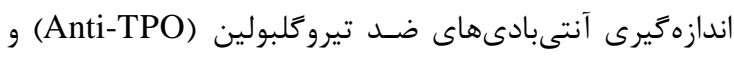

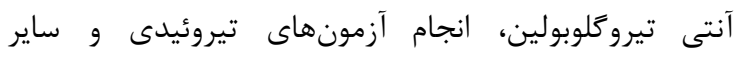

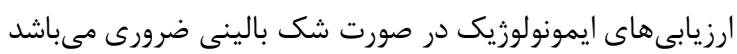

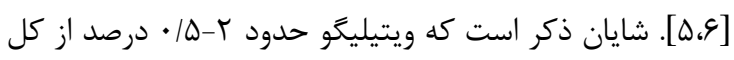

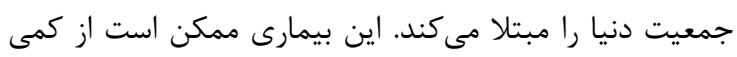

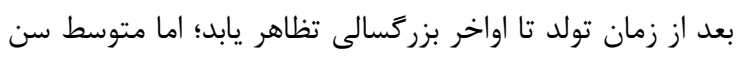

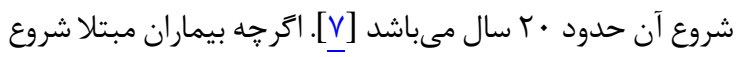

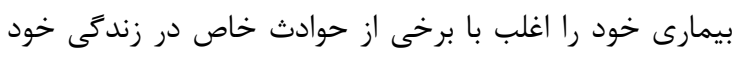

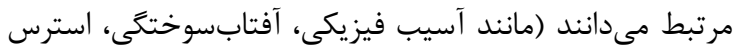

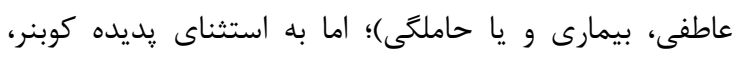

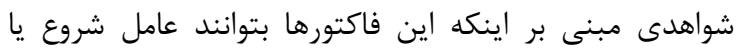
تسريع كننده ويتيليكو باشند وجود ندارد [1]. روشهاى درمانى متفاوتى براى بيمارى ويتيليكو بيشنهاد

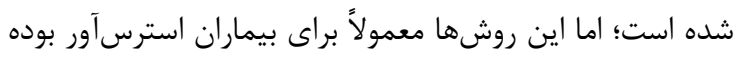

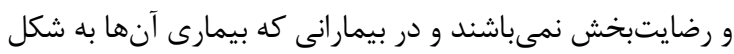

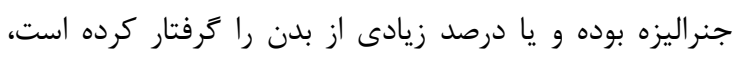

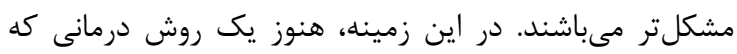

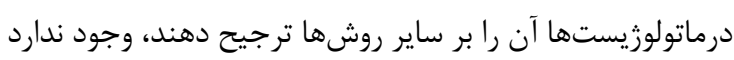

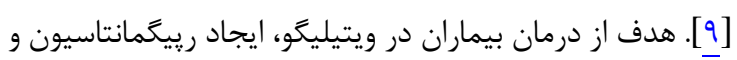

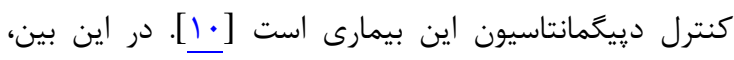

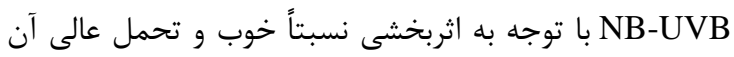

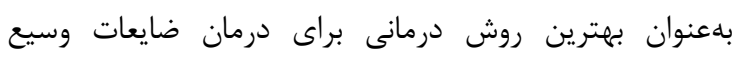

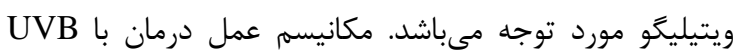

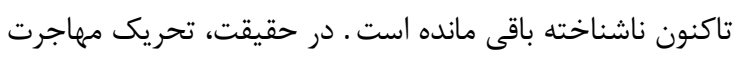

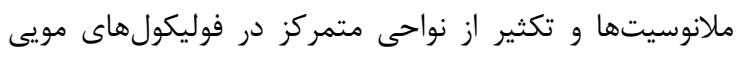

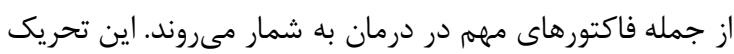

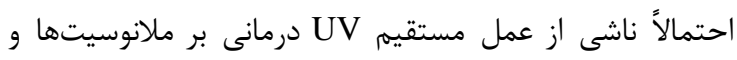

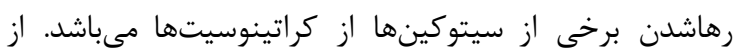
سوى ديگر براساس تأكيد بر منشأ اتوايميون ويتيليگو، احتمالاً

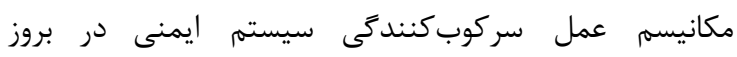

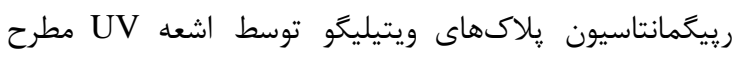

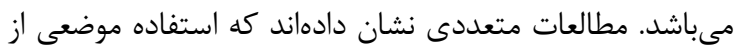

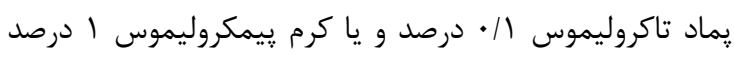

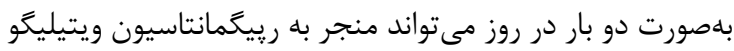

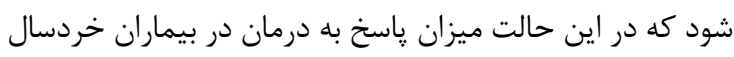


آنها دو ضايعه دوطرفه قرينه كه از نظر سايز و رنگ مشابه با

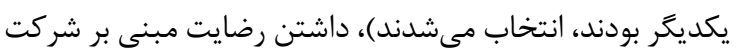

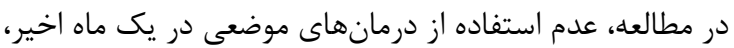

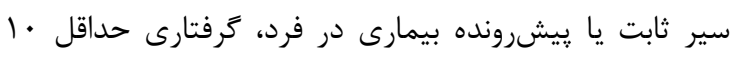

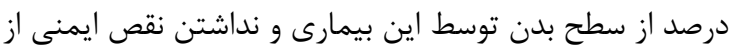

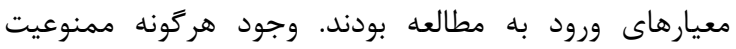

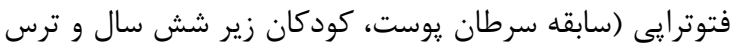

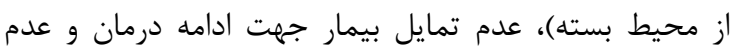

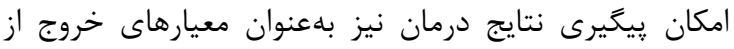
مطالعه در نظر كرفته شدند.

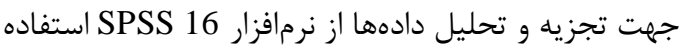

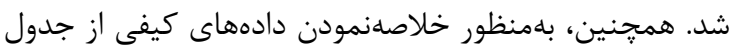

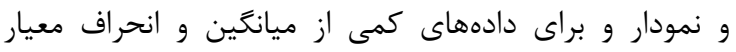

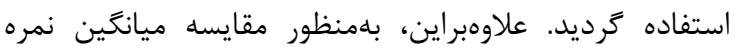

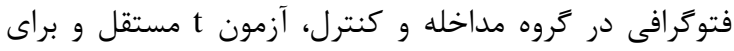

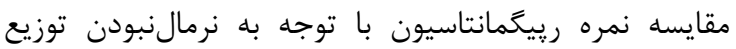

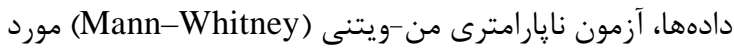
استفاده قرار گرفت. جهت مقايسه ميانگين نمره

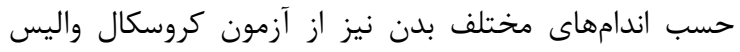
استفاده شد و سطح معنادارى در اين (Kruskal-Wallis) مطالعه كمتر از ه • • • لحاظ گرديد.
مربع تعيين مىشد و سيس براساس ايجاد يا عدم ايجاد اريتم

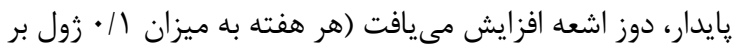

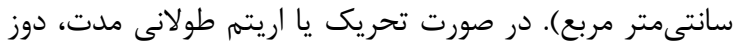

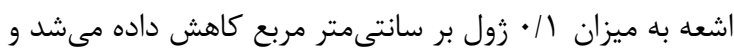

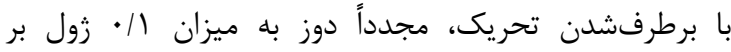

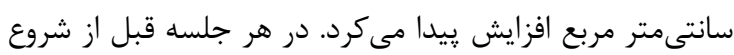

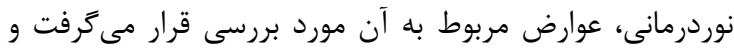

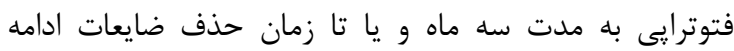
مىيافت. هر بيمار يك بار در ابتداى درمان و سيس هر هر يك ماه ماه

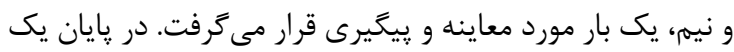

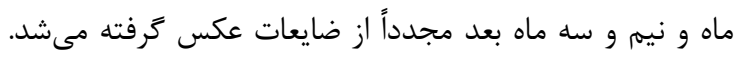

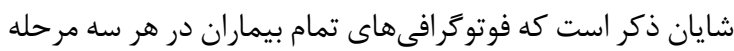

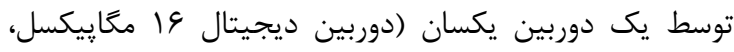

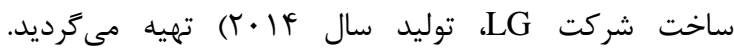

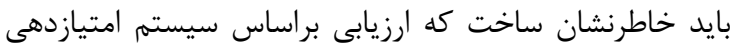
باني (Vitiligo Area and Scoring Index) VASI اندازهگيرى و ثبت سايز ضايعات با استفاده از خط كش و مقايسه

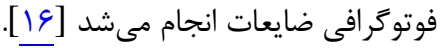

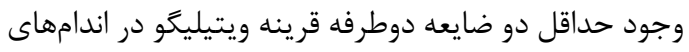

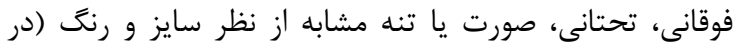

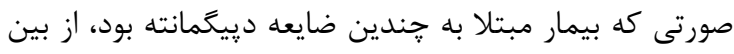

جدول ا: سيستم امتيازدهى VASI

\begin{tabular}{|c|c|c|}
\hline 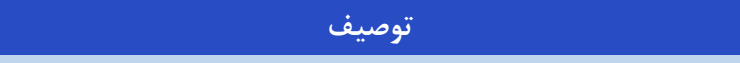 & درصد رييًَمانتاسيون & 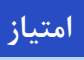 \\
\hline عدم تغيير در ناحيه دِيخمانته & - & • \\
\hline وجود لكههايى از ريِگمانتاسيون يا مقعرشدن حاشيه ناحيه دييگمانته & 1. & 1 \\
\hline نواحى ريّيخمانته نسبت به نواحى دييخمانته كمتر هستند & ra & $r$ \\
\hline نواحى رِيخمانته تقريباً با نواحى دييخمانته برابر مىباشند & $\Delta \cdot$ & r \\
\hline نواحى رييخمانته بيشتر از نواحى باقى مانده دِيخمانته هستند & VQ & f \\
\hline برخى از لكههاى دييخمانته هنوز باقى هستند & q. & $\Delta$ \\
\hline رييخمانتاسيون كامل & $1 \cdots$ & 9 \\
\hline
\end{tabular}

كافته ها

جدول r: فراوانى بيماران مبتلا به ويتيليخو مورد مطالعه بر حسب محل ابتلا

\begin{tabular}{|c|c|c|}
\hline درصد & تعداد & محل ابتلا \\
\hline$r \& / V$ & $\wedge$ & اندام فوقانى \\
\hline Fr/T & Ir & اندام تحتانى \\
\hline$r$. & 4 & تنه \\
\hline 1. & r & جينهاى بدن \\
\hline $1 \ldots$ & $r$. & مجموع \\
\hline
\end{tabular}

ويتيليگو، ضايعه مورد مداخله و كنترل در بدو درمان معادل

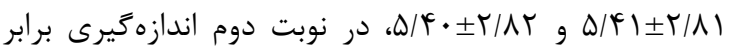

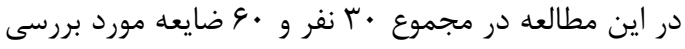

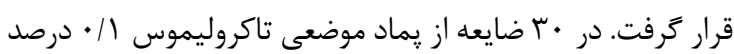
و در · r ضايعه ديگر در سمت قرينه از يماد اوسرين استفاده شد.

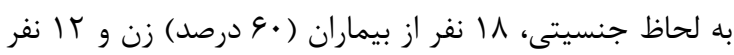

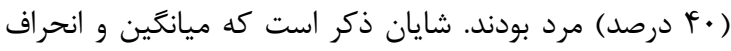

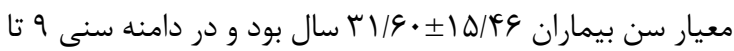

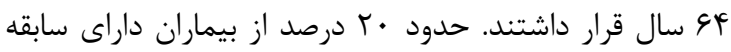

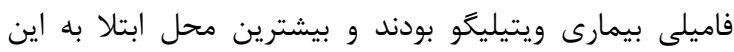

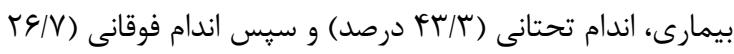

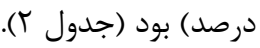
ميانگين و انحراف معيار اندازه فتوكرافى بيماران بـان مبتلا به 
ميانگين نمره VASI گروه مداخله و كنترل در يك ماه و نيم

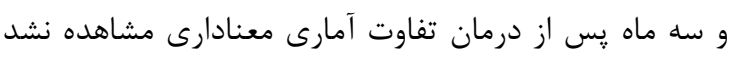

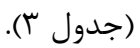

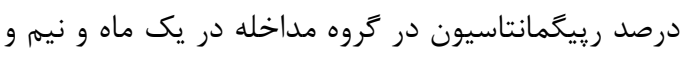

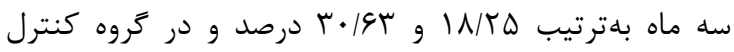

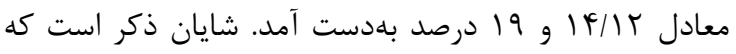

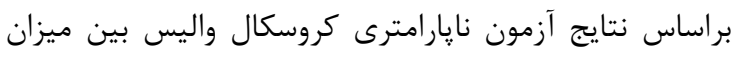

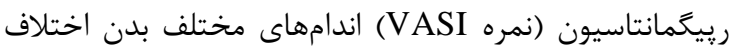

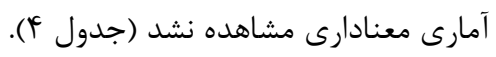

با باد

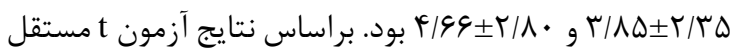

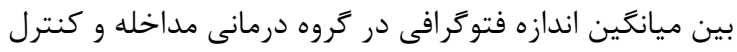

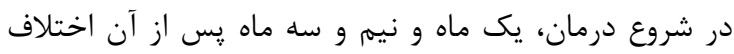

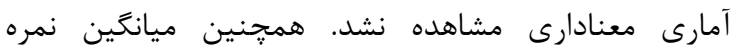

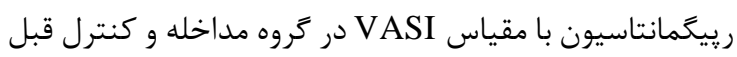

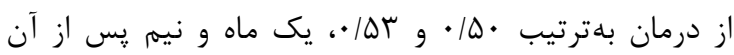

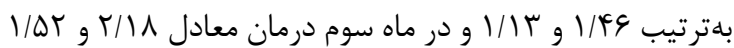

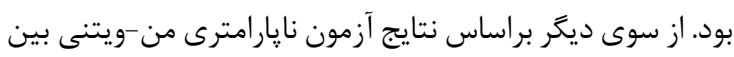

جدول س: مقايسه اندازه ضايعات براساس سانتىمتر در فتوكرافى و نمره VASI بيماران مبتلا به ويتليكو بر حسب زمان اندازمخيرى و گروه درمانى

\begin{tabular}{|c|c|c|c|c|c|}
\hline \multicolumn{2}{|c|}{ نمره VASI } & \multicolumn{2}{|c|}{ فتو } & \multirow{2}{*}{ تروه درمانى } & \multirow{2}{*}{ ـمان اندازه ارزيابى } \\
\hline سطح معنادارى & ميانگين (انحراف معيار) & سطح معنادارى & ميانَين (انحراف معيار) & & \\
\hline •/V৭1 & $\begin{array}{l}(\cdot / \Delta \mid) \cdot / \Delta \cdot \\
(\cdot|\Delta|) \cdot \mid \Delta r\end{array}$ & .1994 & $\begin{array}{l}(Y / \Lambda I) \Delta / \mathcal{F} \\
(Y / \Lambda T) \Delta / \mathcal{F} .\end{array}$ & مداخله & \\
\hline$\cdot / r \Delta V$ & $\begin{array}{l}(1 / T F) 1 / 49 \\
(1 / \cdot 1) 1 / 1 T\end{array}$ &.$|9|$. & $\begin{array}{l}(Y / V Y) F / \Delta q \\
(Y / A Y) F / Q \varphi\end{array}$ & كداخله & 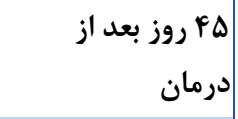 \\
\hline & $\begin{array}{l}(1 / \Delta V) T / 1 \Lambda \\
(I / T I) I / \Delta T\end{array}$ & . & $\begin{array}{l}(Y / T \Delta) \Gamma / \Lambda \Delta \\
(Y / \Lambda \cdot) \Psi / \varphi \hookrightarrow\end{array}$ & مداخله & درمان ماه يس از \\
\hline
\end{tabular}

جدول Fا: مقايسه نمره VASI بيماران مبتلا به ويتيليخو تحت درمان تركيبى با فتوترايى و קماد تاكروليموس / / درصد در يك ماه و نيم و سه ماه

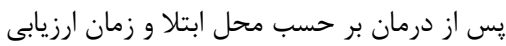

\begin{tabular}{|c|c|c|c|c|c|}
\hline خله & سه ماه يس از & ز مداخله & يك ماه و نيم يس & تهدا & محل ابتلا \\
\hline |سطح معنادارى & ميانَين (انحراف معيار) & سطح معنادارى & ميانتين (انحراف معيار) & & \\
\hline & $(1 / .9) 1 / r V$ & & $(1 / 11) 1 / \cdot r$ & $\wedge$ & اندام فوقانى \\
\hline & $(1 / 19) 1 / 9 r$ & & $(\cdot / 9 \Delta) 1 / 19$ & ir & اندام تحتانى \\
\hline$\cdot 11 \cdot 1$ & $(1 / V \Lambda) T / V \Delta$ &.$/ I V T$ & $(\cdot / A T) \mid / \& V$ & 9 & تنه \\
\hline & r & & س & r & جينهاى بدن \\
\hline & $(1 / \Delta V) T / \Lambda \Lambda$ & & $(1 / T F) 1 / F \&$ & $r$. & مجموع \\
\hline
\end{tabular}

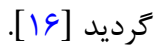

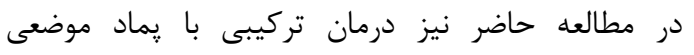

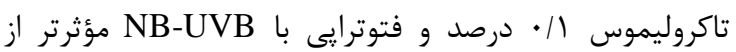

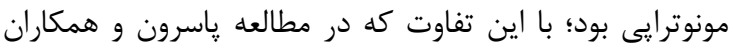

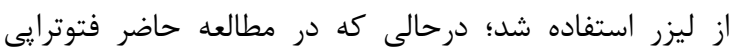
NB-UVB

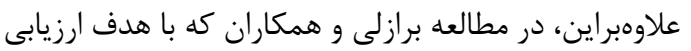

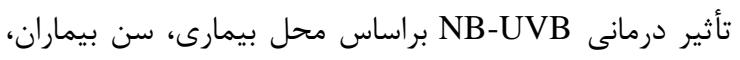

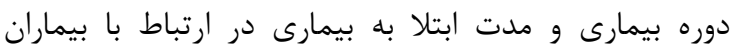

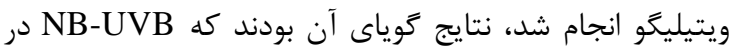
برخى از نقاط بدن تأثير بهترى دارد و بيمار انى كه سن يإيينترى
نتايج مطالعه حاضر نشان دادند كه درمان تركيبى با يماد

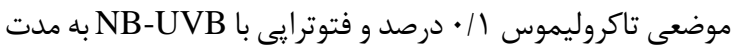

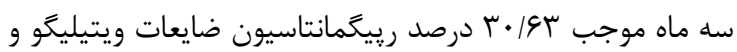

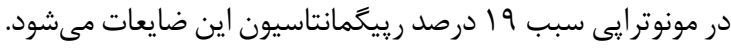

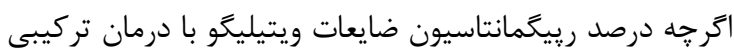

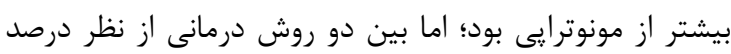

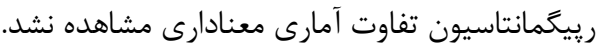

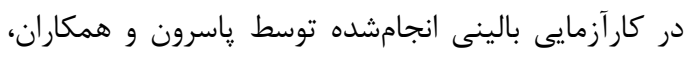

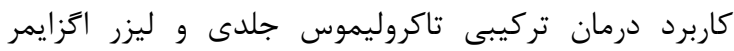
(308-nm Excimer)

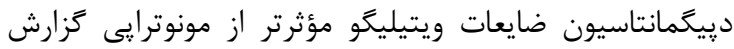


مجيد و همكاران مشابهت داشت؛ با اين تفاوت كه حجم نمونه و

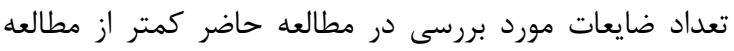
مذكور بود. علاوهبراين، در مطالعه حاضر ضايعه سمت مدات مداخله ماته (ج) يا راست) بهصورت تصادفى انتخاب شد؛ اما در مطالعه مجيد

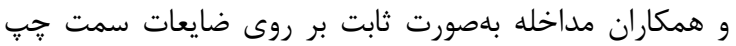
صورت گرفت و سمت راست بهعنوان كنترل در نظر كرفته شد.

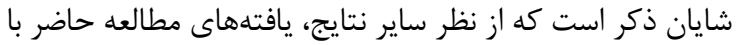
نتايج مطالعه مجيد و همكاران مطابقت دارد.

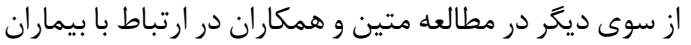

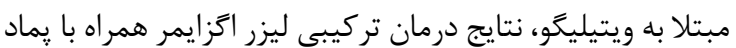

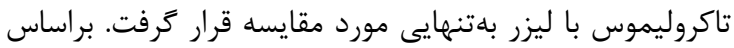

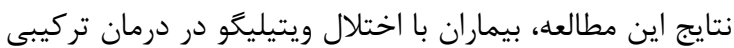

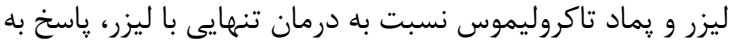

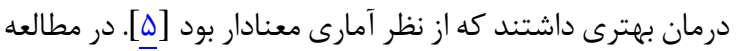

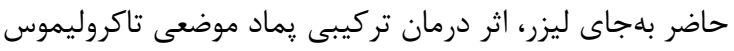

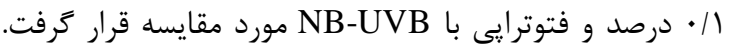

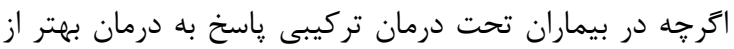

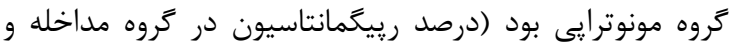

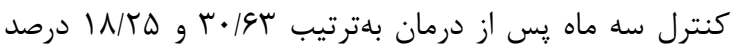

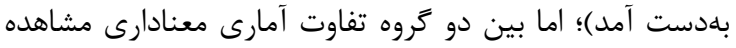

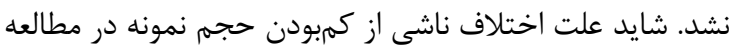
حاضر نسبت به مطالعه متين و همكاران و يا تفاوت در نوع اشعه درمانى (ليزر در مقابل NB-UVB) باشد.

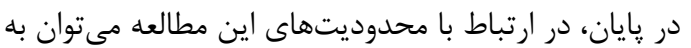

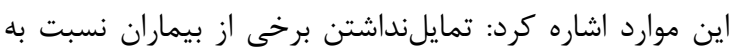

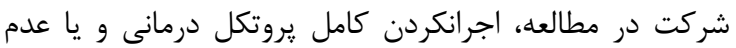
بركشت جهت ييخيرى نتايج درمان توسط آنها.

\section{نتيجه تيرى}

استفاده روزانه دو بار از يماد // • درصد تاكروليموس در

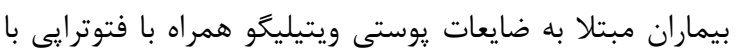

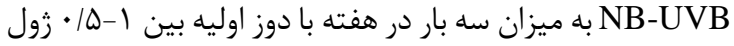

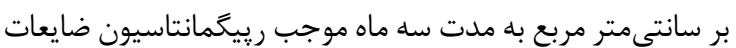

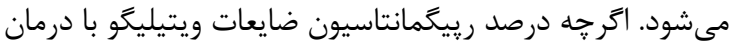

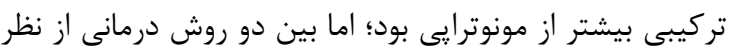

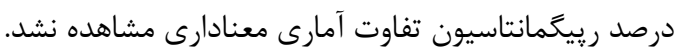

\section{تشكر و قلرواذى}

اين مقاله بركرفته از پاياننامه دوره دكترى تخصصى رشته رشته

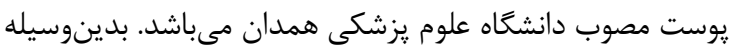

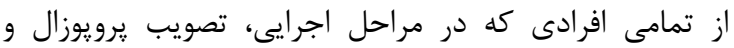

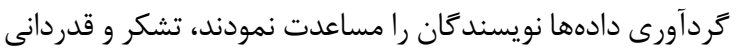
مى نويسندگان در تعارض نمى باشد. نيان
دارند و به تازگى درمان خود را آغاز نمودهاند، به درمان بهتر ياسخ مى دهنيد [IV] در مطالعه حاضر همسو با نتايج مطالعه برازلى و همكاران،

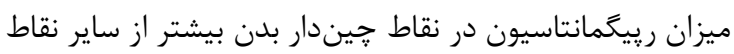

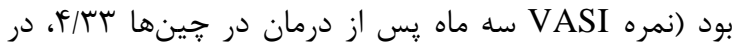

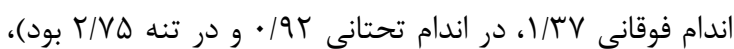

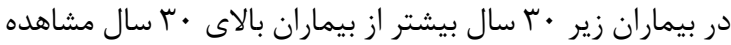

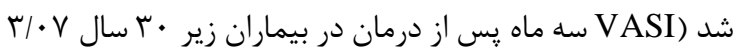

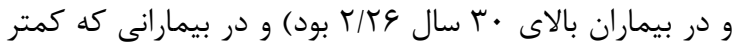

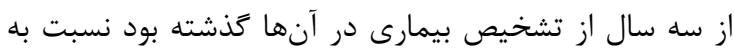

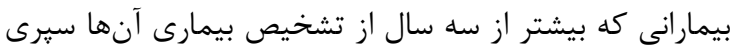

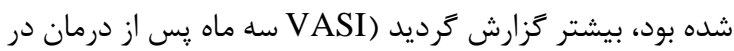

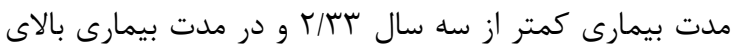

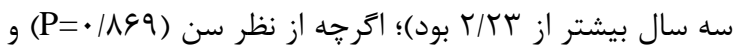

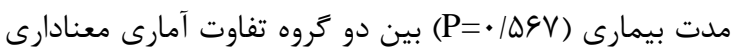
مشاهده نشد. از سوى ديگر، در مطالعه فاى و همكاران كار آيى و قابليت

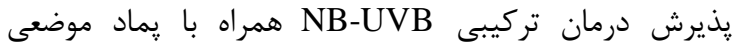

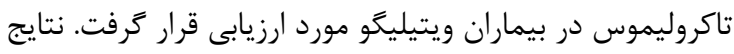

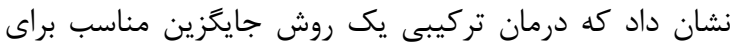

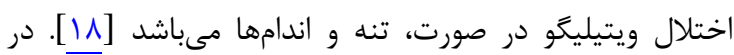
مطالعه حاضر نيز همسو با يافتههاى فاى و همكاران، نتايج درمان

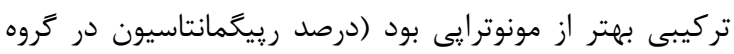

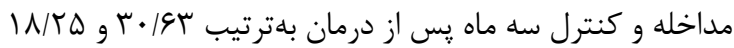

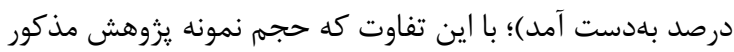
بيشتر از مطالعه حاضر بود.

همجنين، در كارآزمايى بالينى دوسوكورى كه توسط نورد

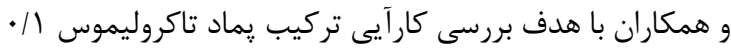

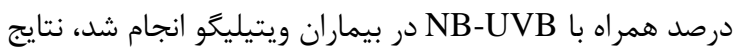

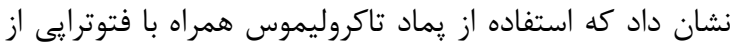

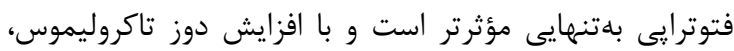

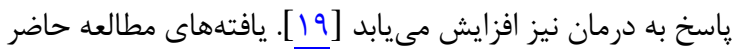

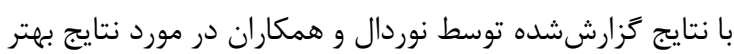

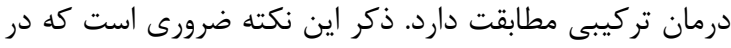

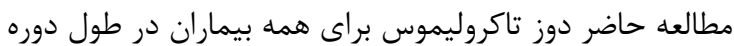

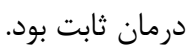
علاوهبراين، در مطالعه مجيد و ونمكاران بئ بيمارانى كه

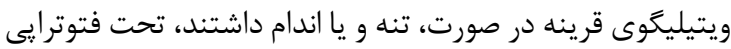

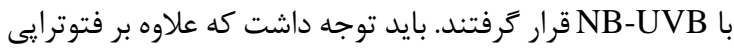

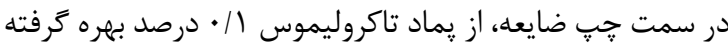
شد و در سمت راست از هيج پِمادى استفاده نخرديد. نتايج

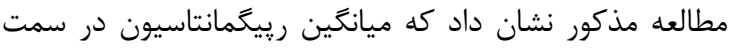

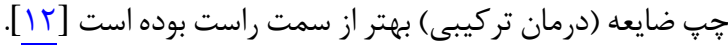
مطالعه حاضر از نظر روش انجام كار و شيوه مداخله با مطالعه 


\section{REFERENCES}

1. Adotama P, Zapata L Jr, Currimbhoy S, Hynan LS, Pandya AG. Patient satisfaction with different treatment modalities for vitiligo. J Am Acad Dermatol. 2015;72(4):732-3. PMID: 25773415 DOI: 10.1016/j.jaad.2014.12.012

2. Alhowaish AK, Dietrich N, Onder M, Fritz K. Effectiveness of a 308-nm excimer laser in treatment of vitiligo: a review. Lasers Med Sci. 2013;28(3):1035-41. PMID: 22892613 DOI: 10.1007/s10103-012-1185-1

3. Silverberg JI, Silverberg NB. Topical tacrolimus is more effective for treatment of vitiligo in patients of skin of color. J Drugs Dermatol. 2011;10(5):507-10. PMID: 21533297

4. Silverberg NB. Pediatric vitiligo. Pediatr Clin North Am. 2014;61(2):347-66. PMID: 24636650 DOI: 10.1016/j.pcl. 2013.11.008

5. Matin M, Latifi S, Zoufan N, Koushki D, Mirjafari Daryasari SA, Rahdari F. The effectiveness of excimer laser on vitiligo treatment in comparison with a combination therapy of Excimer laser and tacrolimus in an Iranian population. $J$ Cosmet Laser Ther. 2014;16(5):241-5. PMID: 25046236 DOI: $10.3109 / 14764172.2014 .946049$

6. Huang H, Wang X, Ding X, Xu Q, Hwang SK, Wang F, et al. Effect and mechanism of tacrolimus on melanogenesis on A375 human melanoma cells. Chin Med J. 2014; 127(16):2966-71. PMID: 25131236

7. Slater SF, Hult G, Olson EM. Factors influencing the relative importance of marketing strategy creativity and marketing strategy implementation effectiveness. Indust Market Manag. 2010;39(4):551-9. DOI: 10.1016/j.indmarman.2008.03.007

8. Alikhan A, Felsten LM, Daly M, Petronic-Rosic V. Vitiligo: a comprehensive overview: part I. Introduction, epidemiology, quality of life, diagnosis, differential diagnosis, associations, histopathology, etiology, and workup. J Am Acad Dermatol. 2011;65(3):473-91. PMID: 21839315 DOI: 10.1016/j.jaad.2010.11.061

9. Hartmann A, Lohberg L, Keikavoussi P, Eichner S, Schuler $\mathrm{G}$. Treatment of generalised vitiligo with tacrolimus $0.1 \%$ ointment vs. UVB intense pulsed light phototherapy: a pilot study. Acta Derm Venereol. 2014;94(5):585-7. PMID: 24473666 DOI: $10.2340 / 00015555-1740$

10. Juan D, Qianxi X, Zhou C, Jianzhong Z. Clinical efficacy and safety of tacrolimus ointment in patients with vitiligo. $J$ Dermatol. 2011;38(11):1092-4. PMID: 21895744 DOI: 10.1111/j.1346-8138.2010.01124.x
11. Udompataikul $\mathrm{M}$, Boonsupthip $\mathrm{P}$, Siriwattanagate $\mathrm{R}$. Effectiveness of $0.1 \%$ topical tacrolimus in adult and children patients with vitiligo. J Dermatol. 2011;38(6):536-40. PMID: 21352308 DOI: $10.1111 / \mathrm{j} .1346-8138.2010 .01067 . \mathrm{x}$

12. Majid I. Does topical tacrolimus ointment enhance the efficacy of narrowband ultraviolet B therapy in vitiligo? A left-right comparison study. Photodermatol Photoimmunol Photomed. 2010;26(5):230-4. PMID: 20831696 DOI: 10.1111/j.1600-0781.2010.00540.x

13. Nistico S, Chiricozzi A, Saraceno R, Schipani C, Chimenti S. Vitiligo treatment with monochromatic excimer light and tacrolimus: results of an open randomized controlled study. Photomed Laser Surg. 2012;30(1):26-30. PMID: 22054204 DOI: 10.1089/pho.2011.3029

14. Berti S, Buggiani G, Lotti T. Use of tacrolimus ointment in vitiligo alone or in combination therapy. Skin Ther lett. 2009;14(4):5-7. PMID: 19585060

15. Kim CR, Lee DY. Combination of narrow-band ultraviolet B and topical tacrolimus is effective for segmental vitiligo. Int J Dermatol. 2013;52(10):1279-81. PMID: 24073911 DOI: 10.1111/j.1365-4632.2011.05132.x

16. Passeron T, Ostovari N, Zakaria W, Fontas E, Larrouy JC, Lacour JP, et al. Topical tacrolimus and the 308-nm excimer laser: a synergistic combination for the treatment of vitiligo. Arch Dermatol. 2004;140(9):1065-9. PMID: 15381545 DOI: 10.1001/archderm.140.9.1065

17. Brazzelli V, Antoninetti M, Palazzini S, Barbagallo T, De Silvestri A, Borroni G. Critical evaluation of the variants influencing the clinical response of vitiligo: study of 60 cases treated with ultraviolet B narrow-band phototherapy. J Eur Acad Dermatol Venereol. 2007;21(10):1369-74. PMID: 17958843 DOI: 10.1111/j.1468-3083.2007.02278.x

18. Fai D, Cassano N, Vena GA. Narrow-band UVB phototherapy combined with tacrolimus ointment in vitiligo: a review of 110 patients. J Eur Acad Dermatol Venereol. 2007;21(7):916-20. PMID: 17659000 DOI: 10.1111/j.14683083.2006.02101.x

19. Nordal EJ, Guleng GE, Ronnevig JR. Treatment of vitiligo with narrowband-UVB (TL01) combined with tacrolimus ointment $(0.1 \%)$ vs. placebo ointment, a randomized right/left double-blind comparative study. J Eur Acad Dermatol Venereol. 2011;25(12):1440-3. PMID: 21466589 DOI: 10.1111/j.1468-3083.2011.04002.x 